\title{
Multidimensional versus unidimensional models of emotional contagion: the Emotional Contagion Scale in a Polish sample
}

\author{
Monika Wróbel ${ }^{1 \cdot A, B, C, D, E, F}$, Lars-Olov Lundqvist ${ }^{2 \cdot C, D, E, F}$ \\ 1: University of Lodz, Lodz, Poland \\ 2: Örebro University, Örebro, Sweden
}

BACKGROUND

The Emotional Contagion Scale (ECS) measures individual differences in susceptibility to catching emotions expressed by others. Although initially the scale was reported to have a unidimensional structure, recent validation studies have suggested that the concept of emotional contagion is multidimensional. The aim of the study was therefore to test whether the structure of the ECS in a Polish sample corresponds with that observed for other non-English speaking populations.

\section{PARTICIPANTS AND PROCEDURE}

The scale, translated into Polish, was completed by 633 university students in four independent samples. To investigate the factor structure of the ECS, confirmatory factor analyses of five alternative models were conducted.

\section{RESULTS}

The results supported a multifaceted solution, which confirmed that susceptibility to emotional contagion may be differentiated not only across positive vs. negative states but also across discrete emotions. Moreover, the verification of internal consistency, test-retest reliability and construct validity of the Polish version indicated that its parameters are acceptable and comparable with the characteristics of other adaptations.

\section{CONCLUSIONS}

The Polish ECS, together with other adaptations of the scale, shows that the construct developed in the United States can be successfully measured in other cultural contexts. Thus, the Polish version can be treated as a useful tool for measuring individual differences in susceptibility to emotional contagion.

\section{KEY WORDS}

emotional contagion; discrete emotions; individual differences

CORRESPONDING AUthor - Monika Wróbel, Institute of Psychology, University of Lodz, 10/12 Smugowa Str., 91-433 Lodz, Poland, e-mail: mwrobel@uni.lodz.pl

AUthors' CONTRIBUtion - A: Study design - B: Data collection - C: Statistical analysis - D: Data interpretation ·

E: Manuscript preparation · F: Literature search · G: Funds collection

TO CITE THIS ARTICLE - Wróbel, M. \& Lundqvist, L.-O. (2014). Multidimensional versus unidimensional models of emotional contagion: the Emotional Contagion Scale in a Polish sample. Current Issues in Personality Psychology, 2(2), 81-91. 


\section{BACKGROUND}

Emotional contagion describes the widely observed phenomenon of one person's feelings being influenced by surrounding people's emotions (Hatfield, Cacioppo \& Rapson, 1994). Studies conducted in various cultural contexts have shown that the process occurs in a broad range of social situations (e.g. interactions between roommates, employers and employees, or people interacting on-line; e.g. Anderson, Keltner \& John, 2003; George, 1990; Chmiel et al., 2011) and may be observed not only in faceto-face contacts (e.g. Barsade, 2002) but also when pictures of facial expressions (e.g. Lundqvist, 1995; Lundqvist \& Dimberg, 1995; Wild, Erb \& Bartels, 2001), videos (e.g. Papousek, Schulter \& Lang, 2009), audio recordings (e.g. Neumann \& Strack, 2000), or music (Lundqvist, Carlsson, Hilmersson \& Juslin, 2009) are used.

According to the theory, emotional contagion involves two mechanisms: emotional expression mimicry and afferent feedback (Hatfield et al., 1994). The former refers to the fact that exposure to another person's facial, vocal, or postural expression can result in automatic imitation of the expression. Micro-expressions following such mimicry are automatically decoded, which, in turn, sets off the latter mechanism. Through this process, the expressions are translated into feelings, which leads to emotional convergence between the sender and the receiver of emotion. The automatic nature of these mechanisms differentiates emotional contagion from empathy, which is based on not only automatic but also controlled processes (Doherty, 1997; Hatfield et al., 1994). So far, numerous studies have confirmed the existence of both emotional expression mimicry and afferent feedback (e.g. Chartrand \& Bargh, 1999; Dimberg, Thunberg \& Elmehed, 2000; Neumann \& Strack, 2000; Stepper \& Strack, 1993).

Although transfer of emotional states between people is a common phenomenon, susceptibility to it is an individual trait (Dimberg \& Lundqvist, 1990; Doherty, 1997). Hatfield and colleagues (1994) suggest that people should be more likely to catch emotions of those who surround them if they are more emotionally reactive, aware of their own feelings and able to decode and imitate emotional expressions of others. Individuals should also be more susceptible to emotional contagion if their selves are construed as interrelated with others and if their attention is riveted on others (Lundqvist, 2008). This suggests that the propensity for emotional contagion should be associated with traits indicating high emotionality (such as empathy, neuroticism, emotional reactivity) and orientation towards other people (such as extraversion, agreeableness, femininity).

\section{THE EMOTIONAL CONTAGION SCALE: A UNIDIMENSIONAL OR MULTIDIMENSIONAL MEASURE?}

In order to assess individual differences in the tendency to converge emotionally with others, Doherty (1997) developed a 15-item self-report measure - the Emotional Contagion Scale (ECS). The items refer to various situations in which people are exposed to emotions of others (e.g. Being around happy people fills me with happy thoughts; I tense when overhearing an angry quarrel; Listening to the shrill screams of a terrified child in the dentist's waiting room makes me feel nervous) and are scored on 5-point Likert scales, from not at all to always. Based on exploratory factor analysis, the ECS was initially reported to have a unidimensional structure with item loadings from 0.49 to 0.69 . The factor was characterized by high internal consistency (Cronbach's $\alpha=0.90$ ) and test-retest reliability $(r(41)=0.84)$. Although a single-factor solution best fitted the data, a twodimensional solution, with negative emotions (anger, fear, sadness) and positive emotions (love, happiness) factors (Cronbach's $\alpha$ s $=0.80$ and 0.82 , respectively), was also obtained (Doherty, 1997). However, validation studies conducted in several non-English speaking countries yielded multi-dimensional structures of the ECS (Gouveia, Gouveia, Guerra, Santos \& Medeiros, 2007; Lundqvist, 2006; Lundqvist \& Kevrekidis, 2008; Rueff-Lopes \& Caetano, 2012; Kimura, Yogo \& Daibo, 2007). Lundqvist and colleagues (Lundqvist, 2006, Lundqvist \& Kevrekidis, 2008), using confirmatory factor analysis, found support for two different yet related models: a five-factor model with the factors representing every emotion in the ECS, and a hierarchical two-factor model with two second-order factors: a positive-emotion factor that included primary factors of happiness and love, and a negative-emotion factor that included primary factors of anger, fear, and sadness. This suggests that susceptibility to emotional contagion may be differentiated not only across positive vs. negative states but also across discrete emotions. Although discrete emotion theories vary, most of them state that there is a limited number of culturally universal primary emotions which are unique experiential states that result from distinct causes and can be distinguished by emotional expressions (e.g. Ekman, 1992; Izard, 1992). Given that emotional contagion results from imitation of emotional expressions and facial feedback, it should lead to the activation of emotions (e.g. happiness, love, anger, sadness, and fear) rather than just positive vs. negative states. For instance, it might be possible that some individuals are highly prone to catching anger and at the same time resistant to catching sadness. However, there is no consensus on the categorical vs. dimensional nature of the facial feedback mechanism 
- although some researchers think that muscle movements can evoke discrete emotions, others claim that the effects of facial feedback are limited to positive vs. negative states (Laird, 1984; Winton, 1986). The studies on emotional contagion are also inconclusive - while some of them confirm that people catch diverse emotions (Lundqvist \& Dimberg, 1995; Papousek et al., 2009), others do not support it (Hess \& Blairy, 2001).

The results are less ambiguous with regard to gender differences in self-rated susceptibility to emotional contagion. Most studies have demonstrated that women score higher on the ECS no matter if the full scale (Doherty, 1997; Rueff-Lopes \& Caetano, 2012) or its subscales are taken into account (Lundqvist, 2006; Lundqvist \& Kevrekidis, 2008). This pattern of results is in line with the fact that women usually declare that they are more emotional and more people-oriented than men (Cross \& Markus, 1993; Shields, 2002). The ECS was also reported to be linked to other measures of emotionality and orientation towards others such as empathy (Doherty, 1997; Kimura et al., 2007; Rueff-Lopes \& Caetano, 2012), neuroticism, extraversion, and femininity (Doherty, 1997).

\section{THE PRESENT STUDY}

The main purpose of the present study was to test whether the concept of emotional contagion in a Polish culture corresponds with that observed for other non-English speaking populations. Our previous preliminary exploratory factor analyses on the ECS revealed two positively correlated factors: positive emotions and negative emotions (Wróbel, 2007, 2009). In the present study a series of confirmatory factor analyses - which offer a more rigorous test than exploratory analyses - were conducted. Based on previous findings (Doherty, 1997; Lundqvist, 2006; Lundqvist \& Kevrekidis, 2008), five plausible models were tested: 1 ) a one-factor model (1F) which assumes a one-dimensional structure of the ECS; 2) a two-factor model $(2 \mathrm{~F})$ which divides susceptibility to emotional contagion into two related dimensions: positive and negative emotions; 3 ) a five-factor model (5F) which assumes that susceptibility to emotional contagion is multifaceted across five emotions; 4) a hierarchical one-factor model $(1+5 \mathrm{~F})$ with one secondorder factor and five primary factors representing five emotions; and 5) a hierarchical two-factor model $(2+5 \mathrm{~F})$ with two second order factors - positive emotions and negative emotions - and five primary factors of happiness, love, anger, fear, and sadness.

We also examined construct validity of the ECS with regard to the whole measure as well as five emotion facets. More specifically, it was expected that: 1) women would score higher than men on all the subscales; 2) susceptibility to emotional contagion would be positively linked to variables indicating high emotionality (empathy, neuroticism, emotional reactivity, perseveration, femininity), and negatively related to variables indicating low emotionality and high resistance to external stimuli (masculinity, endurance); 3) traits associated with people-oriented attention (agreeableness, extraversion, femininity) would positively relate to the tendency to converge emotionally with others.

\section{PARTICIPANTS AND PROCEDURE}

\section{MATERIAL AND METHODS}

A total of 633 university students (412 women and $221 \mathrm{men}$ ) in four independent samples participated in the study. We used student samples to make our analyses coherent with other studies on the ECS (Doherty, 1997; Lundqvist, 2006; Lundqvist \& Kevrekidis, 2008). The first sample was made up of 34 bilingual students (28 women, 6 men, $M_{\text {age }}=21.62, S D=2.05$ ). They completed the original ECS and then, after a 21-day break, the Polish translation. These data served to verify linguistic equivalence between the two versions. The second sample consisted of 130 first year psychology students (77 women, 53 men, $M_{\text {age }}=20.85$, $S D=1.77)$ who completed the Polish version twice with a four-week interval. The data from this sample were used to verify test-retest reliability of the scale. Both samples 1 and 2 completed the ECS during time allotted to lectures. The third sample, made up of 249 non-psychology students (175 women, 74 men, $\left.M_{\text {age }}=22.65, S D=2.14\right)$, completed the ECS together with other measures. The students were provided with the questionnaires and asked to return them in closed envelopes within a week. The fourth sample also included non-psychology students (220 individuals, 133 women, 88 men, $\left.M_{\text {age }}=21.79, S D=1.53\right)$. They filled in the ECS along with other questionnaires while waiting for experimental sessions. The data collected in all samples were used to assess factor structure and psychometric features of the ECS. Participation was voluntary and the data were collected anonymously.

The adaptation was divided into two stages. In the first stage, the original scale was translated into Polish by five independent psychologists. The translations were compared and all discrepancies discussed. Then linguistic equivalence between the original and the Polish ECS was verified (for a detailed description of the procedure, see Wróbel, 2007). The aim of the second stage was to analyze factor structure and psychometric properties of the Polish version.

\section{MEASURES}

In order to verify convergent and discriminant validity of the Polish ECS several related variables were measured. Empathy was assessed with a Polish 
adaptation of Davis's (1983) Interpersonal Reactivity Index (Kaźmierczak, Plopa \& Retowski, 2007), which measures cognitive and affective aspects of empathy and consists of three subscales: empathic concern, personal distress, and perspective taking. Emotional reactivity, endurance, and perseveration were measured with the Formal Characteristics of Behavior - Temperament Inventory (FCB-TI) by Zawadzki \& Strelau (1995) stemming from the Regulative Theory of Temperament (Strelau, 1996). Neuroticism, extraversion, and agreeableness originating from the Big Five personality model were assessed with the NEO Five-Factor Inventory (NEO-FFI) (Costa \& McCrae, 1989; Polish adaptation by Zawadzki, Strelau, Szczepaniak \& Śliwińska, 1998), whereas femininity and masculinity were assessed with the Psychological Gender Inventory (Kuczyńska, 1992) based on the well-known Bem Sex-Role Inventory (Bem, 1974). The FCB-TI and the NEO-FFI provide information about additional variables (openness to experience, conscientiousness, briskness, sensory sensitivity, and activity), which relate to orientation towards not only social but also physical stimuli. High levels of these traits are typical of people who are focused on tasks, goals and activities, so it is probable that they pay more attention to sensory aspects of the environment than to the feelings of others. Thus, the scores in these additional subscales were also subjected to analyses although no specific hypotheses concerning them were made. Cronbach's $\alpha$ s for all the measures are given in Table 4.

\section{RESULTS}

\section{LINGUISTIC EQUIVALENCE BETWEEN THE ORIGINAL VERSION AND THE POLISH ECS}

To verify linguistic equivalence between the original ECS and the Polish version, correlation analysis was carried out. Its results indicated that both versions were closely related (Pearson's $r$ s for the full ECS and its subscales between 0.62 and $0.87^{1}$ ). Thus, the Polish version may be treated as linguistically equivalent to the American one.

\section{FACTOR STRUCTURE}

In order to test the tenability of the five proposed models, confirmatory factor analysis (CFA) in IBM SPSS AMOS 20.0 with maximum likelihood estimation of the covariance matrix was performed. Three goodness-of-fit indices were used to evaluate the adequacy of the models: the $\chi^{2}$ test, the root mean square error of approximation (RMSEA), and the comparative fit index (CFI). CFA results are reported in Table 1.

All tested models had significant $\chi^{2}$ values and statistically significant loadings (ranging from 0.40 to 1.07). Two out of five models (5F and $2+5 \mathrm{~F}$ depicted in Figures 1 and 2, respectively) showed the most adequate RMSEA and CFI values. Since these values were comparable, the two models were tested for differences in goodness-of-fit by means of $\chi^{2}$ difference tests. The comparison of the change in $\chi^{2}$ revealed that the five-factor model had a significantly better fit than two second-order factors model $\left(\Delta \chi^{2}(4)=21.58, p<0.001\right)$. Therefore, the multifaceted five-factor model should be preferred over the $2+5 \mathrm{~F}$ model. However, as both models showed adequate fit, further analyses were conducted not only for the five emotion facets and the full ECS but also for the positive and negative emotion subscales.

\section{MEAN SCORES, INTERNAL CONSISTENCY, AND TEST-RETEST RELIABILITY}

The descriptive statistics for the full ECS as well as its subscales are given in Table 2. The highest mean score was found for the love facet, the lowest for the anger facet. Positive emotions and love facets' distributions were leptokurtic. The love facet was also slightly left-skewed.

The full ECS turned out to be characterized by good internal consistency, whereas the positive emotions and negative emotions subscales generated acceptable reliability. With regard to internal consistency of the emotion facets, only love and happiness subscales obtained adequate Cronbach's $\alpha$, whereas for anger, fear, and sadness the coefficients fell between 0.56 and 0.65 . Test-retest correlation coefficients met the criterion for adequate reliability only in the case of the full ECS score, negative emotions, sadness and anger facets. Test-retest reliability of the remaining ECS subscales was considerably lower and therefore somewhat questionable. As predicted, the females rated their susceptibility to emotional contagion as higher than the males did (see Table 3).

\section{CONVERGENT AND DISCRIMINANT VALIDITY}

To assess the Polish ECS's construct validity, the relationships between susceptibility to emotional contagion and potentially related variables were examined (Table 4). The results confirmed the expectations by indicating that the full ECS score was positively related to high emotionality and orientation towards others (empathy, femininity, neuroticism, emotional reactivity, perseveration, agreeableness, and extraversion). It was also negatively linked to masculinity and endurance - the traits associated with low emotionality and high resistance to distraction. The majority of correlations with the rest of personality and temperamental variables turned out to be weaker (or insignificant) except for a negative link between 
Table 1

Summary statistics of confirmatory factor analysis of the emotional contagion scale models

\begin{tabular}{ccccccc}
\hline Model & $d f$ & $\chi^{2}$ & RMSEA & RMSEA 90\% CI & $p$ close fit & CFI \\
\hline One-factor (1F) & 90 & 849.02 & 0.116 & $0.108-0.123$ & $<0.001$ & 0.695 \\
Two-factor (2F) & 89 & 489.49 & 0.084 & $0.077-0.092$ & $<0.001$ & 0.839 \\
Five-factor (5F) & 80 & 191.73 & 0.047 & $0.039-0.056$ & 0.707 & 0.955 \\
Hierarchical models & & & & & & 0.094 \\
One second-order factor (1+5F) & 85 & 254.99 & 0.056 & $0.048-0.064$ & 0.932 \\
Two second-order factors (2+5F) & 84 & 213.21 & 0.049 & $0.041-0.058$ & 0.539 & 0.948 \\
\hline
\end{tabular}

Note. RMSEA - root mean squared error of approximation; CFI - comparative fit index; $90 \% \mathrm{Cl}-90 \%$ confidence interval

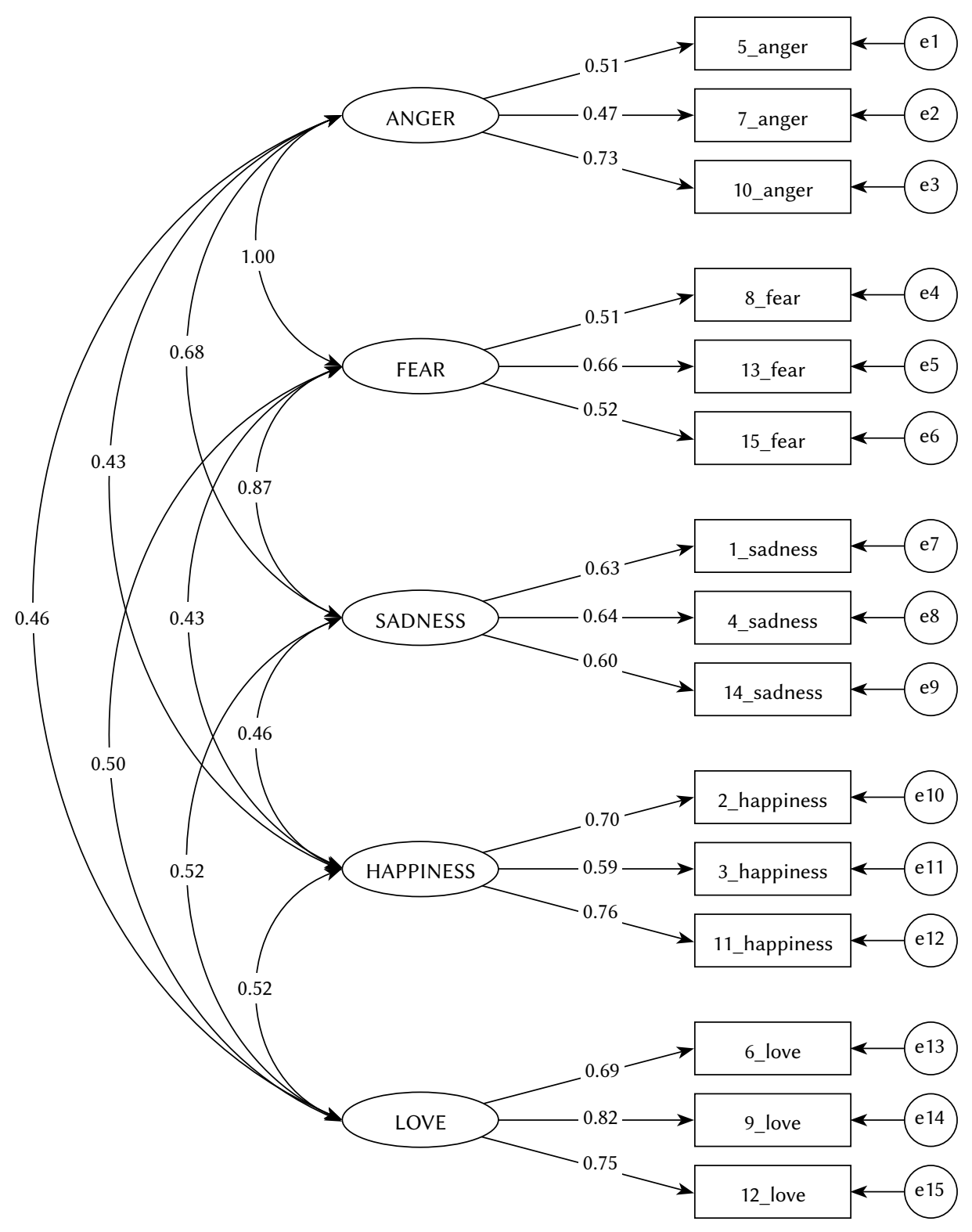

Figure 1. The five-factor model of the Emotional Contagion Scale.

Note. Regression coefficients are standardized 


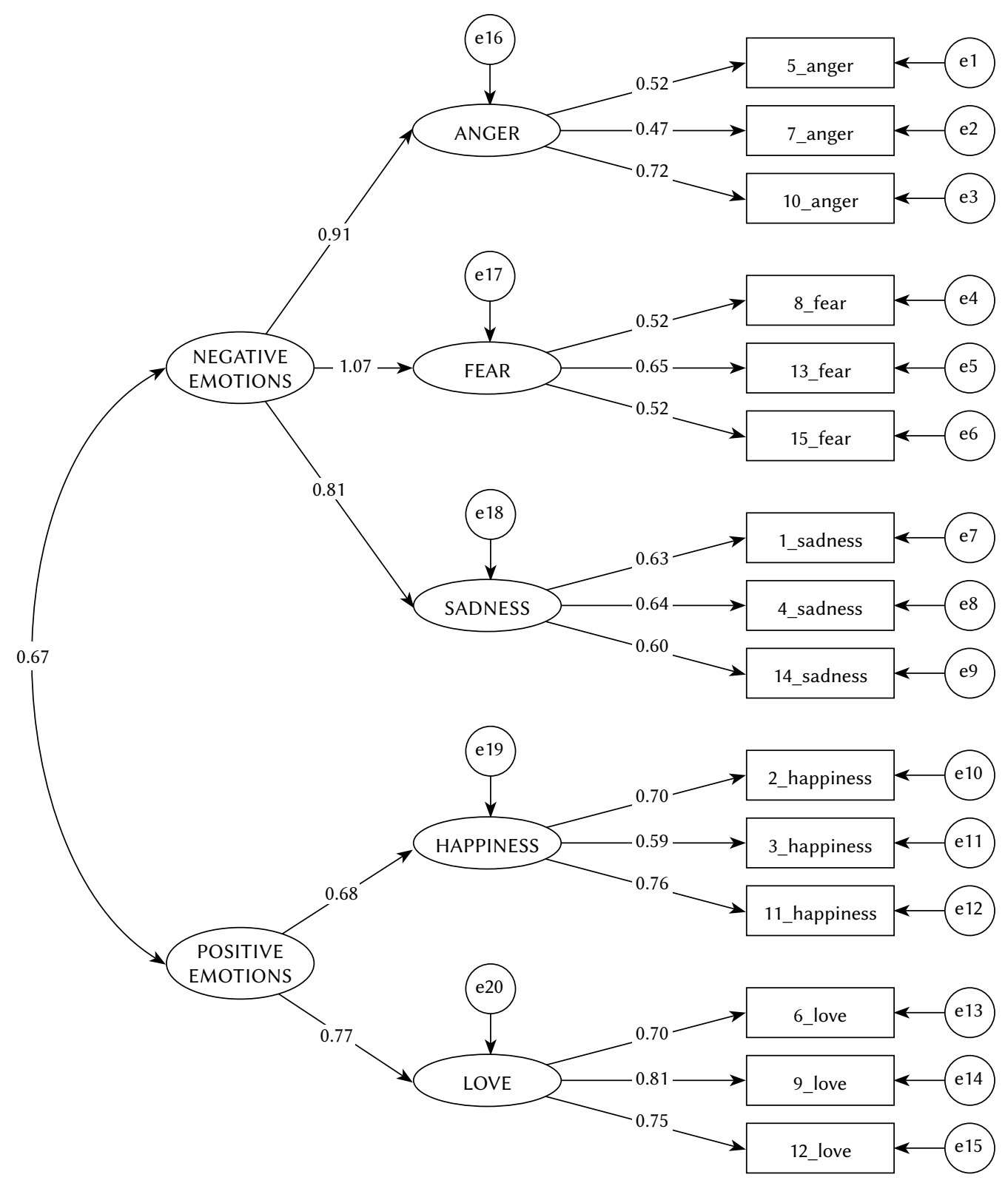

Figure 2. The two second-order factors model of the Emotional Contagion Scale.

Note. Regression coefficients are standardized

briskness and the majority of the ECS facets as well as a positive link between activity, conscientiousness and happiness facets.

Additionally, the pattern of relations was different in the case of negative emotions than in the case of positive emotions. Whereas the former correlated more strongly with traits indicating negative affectivity (neuroticism, emotional reactivity, perseveration) and - apart from sadness - did not correlate with extraversion (positive affectivity), with regard to the latter the opposite pattern of results was found. Moreover, the relationship between the positive and negative emotions subscales and gender dimensions indicated that femininity was positively linked to both aspects of susceptibility to emotional contagion, whereas masculinity was negatively correlated only with negative emotions and - to a lesser extent - happiness.

Finally, correlations between susceptibility to emotional contagion and empathy showed that the highest correlations were observed for empathic concern, which is one of the affective components of empathy. The second affective component, personal distress, was related especially to negative emotion facets. The lowest coefficients were found for the cognitive component of empathy (perspective taking).

Summing up, the Polish ECS was related to the measures of similar constructs. These relationships depended on whether susceptibility to catching negative or positive emotions was taken into consideration. 
Table 2

Descriptive statistics, internal consistency $(n=633)$ and test-retest reliability $(n=130)$ of the Polish ECS

\begin{tabular}{|c|c|c|c|c|c|c|c|c|c|}
\hline Scales & $\begin{array}{c}\text { Number of } \\
\text { items }\end{array}$ & $M$ & $S D$ & Min & Max & Skewness & Kurtosis & Cronbach's $\alpha$ & $\begin{array}{l}\text { Test-retest } \\
\text { reliability } \\
\end{array}$ \\
\hline Full ECS & 15 & 3.49 & 0.59 & 1.47 & 4.87 & -0.35 & 0.10 & 0.84 & $0.79^{* * *}$ \\
\hline $\begin{array}{l}\text { Negative } \\
\text { emotions }\end{array}$ & 9 & 3.06 & 0.73 & 1.00 & 4.78 & -0.14 & -0.29 & 0.79 & $0.82^{* * *}$ \\
\hline Anger & 3 & 2.88 & 0.78 & 1.00 & 5.00 & 0.03 & -0.14 & $\underline{0.57}$ & $0.76^{* * *}$ \\
\hline Fear & 3 & 3.12 & 0.91 & 1.00 & 5.00 & -0.10 & -0.50 & $\underline{0.56}$ & $\underline{0.62}{ }^{* * *}$ \\
\hline Sadness & 3 & 3.17 & 0.95 & 1.00 & 5.00 & -0.16 & -0.63 & $\underline{0.65}$ & $0.85^{* * *}$ \\
\hline $\begin{array}{l}\text { Positive } \\
\text { emotions }\end{array}$ & 6 & 4.15 & 0.62 & 1.33 & 5.00 & -0.99 & $\underline{1.27}$ & 0.76 & $\underline{0.63}^{* * *}$ \\
\hline Happiness & 3 & 4.05 & 0.70 & 1.33 & 5.00 & -0.64 & 0.12 & 0.72 & $\underline{0.61^{* * *}}$ \\
\hline Love & 3 & 4.24 & 0.78 & 1.00 & 5.00 & -1.21 & 1.32 & 0.79 & $0.60^{* * *}$ \\
\hline
\end{tabular}

Note. Critical values are underlined

$* * * p<0.001$

Table 3

Sex differences in the Polish ECS scores

\begin{tabular}{|c|c|c|c|c|c|c|c|c|}
\hline \multirow[t]{2}{*}{ Scales } & \multicolumn{2}{|c|}{ Women $(n=412)$} & \multicolumn{2}{|c|}{ Men $(n=221)$} & \multirow[t]{2}{*}{$t$} & \multirow[t]{2}{*}{$d f$} & \multirow[t]{2}{*}{$p$} & \multirow[t]{2}{*}{ Cohen's $d$} \\
\hline & $M$ & $S D$ & $M$ & $S D$ & & & & \\
\hline Full ECS & 3.66 & 0.52 & 3.17 & 0.59 & 10.81 & 631 & $<0.001$ & 0.86 \\
\hline Negative emotions & 3.28 & 0.64 & 2.65 & 0.70 & 11.39 & 631 & $<0.001$ & 0.91 \\
\hline Anger & 2.97 & 0.75 & 2.73 & 0.82 & 3.74 & 631 & $<0.001$ & 0.28 \\
\hline Fear & 3.36 & 0.85 & 2.69 & 0.87 & 9.24 & 631 & $<0.001$ & 0.74 \\
\hline Sadness & 3.52 & 0.82 & 2.53 & 0.83 & 14.35 & 631 & $<0.001$ & 1.14 \\
\hline Positive emotions & 4.25 & 0.56 & 3.96 & 0.68 & 5.47 & 631 & $<0.001$ & 0.43 \\
\hline Happiness & 4.12 & 0.67 & 3.90 & 0.74 & 3.80 & 631 & $<0.001$ & 0.30 \\
\hline Love & 4.37 & 0.71 & 4.01 & 0.85 & 5.41 & 631 & $<0.001$ & 0.43 \\
\hline
\end{tabular}

\section{DISCUSSION}

The main purpose of the present study was to determine whether the concept of emotional contagion as measured by the Emotional Contagion Scale is one- or multidimensional. CFA revealed that the ECS's factor structure was more complex than it had been initially assumed. Five models based on previous research were subjected to the analysis. When the unidimensional solution proposed by Doherty (1997) was tested, all items obtained acceptable loadings. However, alternative solutions fitted the data better. Adequate goodness-of-fit was obtained for the five-factor model and the two second-order factors model. The 5F model received the best goodness-offit indices and its feasibility relative to the hierarchi- cal model was supported by $\chi^{2}$ difference tests. These findings are consistent with the results obtained in the Swedish (Lundqvist, 2006) and Greek (Lundqvist \& Kevrekidis, 2008) samples. They support the multifaceted model of emotional contagion consistent with discrete emotions theory. Thus, they enable researchers to measure susceptibility to emotional contagion more accurately and precisely than a one-dimensional instrument.

Regarding the reliability of the Polish ECS, the results are slightly less satisfying than the ones reported for the original version. Nevertheless, they are still acceptable for the majority of the subscales. Cronbach's $\alpha$ s for anger, fear and sadness facets, however, do not satisfy the generally accepted criteria for internal consistency. This reflects the results reported 


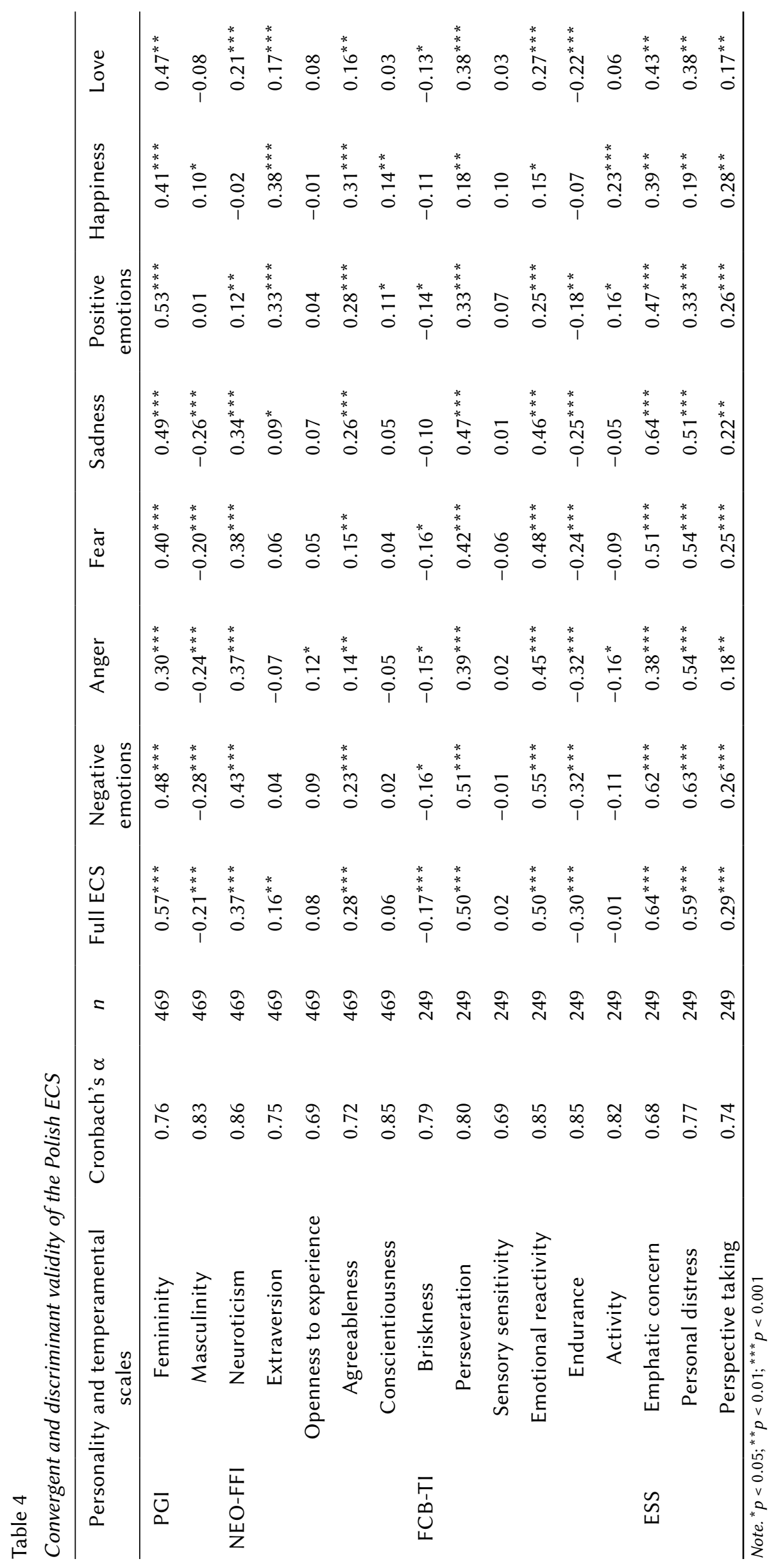


for the Swedish and Greek adaptations and it is not surprising, given that each of the discrete emotions subscales includes only three items (Cortina, 1993). Test-retest reliability of the Polish ECS is somewhat problematic. Only the full ECS, negative emotions, anger and sadness subscales obtained acceptable coefficients indicating that susceptibility to emotional contagion is relatively stable over time. With regard to the remaining subscales, correlation coefficients, although statistically significant, fell below 0.70 . These findings are unexpected in the light of the Swedish results (three-month interval, test-retest reliability coefficients between 0.79 and 0.90) and difficult to interpret for the moment. Unfortunately, Doherty (1997) reports only on test-retest reliability for the full ECS score and the rest of the validation studies did not include test-retest reliability testing.

As for the construct validity of the ECS, women, as predicted, declared higher susceptibility to emotional contagion than men. This pattern of results is identical with the ones found for the original ECS (Doherty, 1997) as well as its adaptations (Gouveia et al., 2007; Lundqvist, 2006; Lundqvist \& Kevrekidis, 2008; Rueff-Lopes \& Caetano, 2012; Kimura et al., 2007). It may be explained by the fact that the ECS falls into the category of retrospective self-reports whose results are to a large extent affected by gender schemata (Shields, 2002). According to them, sensitivity to other people's feelings is ascribed to the feminine role (Best \& Williams, 1993; Cross \& Markus, 1993), whereas the masculine role implies that one should be resistant to negative emotions, but provides no information about the tendency to catch positive feelings. The results of the current study fully confirmed this reasoning by indicating that femininity correlated positively with the ECS scores, whereas masculinity was related negatively only to negative emotions, anger, fear and sadness subscales. Its link with positive emotions turned out to be insignificant or, for the happiness subscale, weak but positive.

The relationships between the ECS and other variables were also consistent with the predictions. They confirmed that the scale correlated positively with the indicators of emotionality and orientation towards other people, which was not observed for the majority of traits related to orientation towards physical (rather than social) stimuli. Thus, the results collected in the Polish sample brought additional support for Hatfield and colleagues' (1994) propositions by indicating that traits closely linked to tender-mindedness, sensitivity to others, and altruism were associated with the tendency to converge emotionally with other people. The data also revealed that susceptibility to emotional contagion was negatively related to briskness. On the one hand, this result may be explained by the fact that people who are constantly in a hurry may have no time to pay attention to the feelings of others. On the other hand, individuals characterized by a high level of briskness should be able to easily and quickly switch to the affective states of those who surround them. Thus, the relationship between briskness and susceptibility to emotional contagion requires further investigation. The results also showed that susceptibility to catching positive emotions was accompanied by positive affectivity, whereas susceptibility to catching negative emotions was accompanied by negative affectivity. Moreover, the study shed some light on the relationship between emotional contagion and empathy, showing that they are closely related yet not identical constructs. The link between susceptibility to emotional contagion and empathy was stronger for its affective than cognitive component, which also supports construct validity of the ECS.

Generally speaking, the Polish ECS can be treated as a useful tool for measuring individual differences in susceptibility to emotional contagion. The Polish version and other adaptations of the ECS show that the construct developed in the United States can be successfully measured in other cultural contexts. They also provide a broader empirical background to our understanding of the complex nature of susceptibility to emotional contagion.

Some limitations of the research should also be noted. Firstly, we used student samples consisting predominantly of young females, which considerably reduces generalizability of the findings. Secondly, construct validity of the ECS was tested only in relation to self-report methods. Thus, future studies should assess the extent to which the ECS predicts individual reactions to experimental tests of susceptibility to emotional contagion. Finally, although the structure of the Polish ECS is to a great extent consistent with the results obtained in other validation studies, it confirms the universality of the ECS only indirectly. Therefore, future studies should verify psychometric properties of the Polish ECS in the cross-cultural context.

\section{ENDNOTES}

1 These results have been previously published in: Wróbel, 2007.

\section{RefERENCES}

Anderson, C., Keltner, D. \& John, O.P. (2003). Emotional convergence between people over time. Journal of Personality and Social Psychology, 84, 1054-1068.

Barsade, S.G. (2002). The ripple effect: emotional contagion and its influence on group behavior. Administrative Science Quarterly, 47, 644-675. 
Bem, S.L. (1974). The measurement of psychological androgyny. Journal of Consulting and Clinical Psychology, 42, 155-162.

Best, D.L. \& Williams, J.E. (1993). A cross-cultural viewpoint. In: A.E. Beall \& R.J. Sternberg (eds.). The Psychology of Gender (pp. 215-248). New York: Guilford Press.

Chartrand, T.L. \& Bargh, J.A. (1999). The chameleon effect: The perception-behavior link and social interaction. Journal of Personality and Social Psychology, 17, 893-910.

Chmiel, A., Sienkiewicz, J., Thelwall, M., Paltoglou, G., Buckley, K., Kappas, A. \& Hołyst, J.A. (2011). Collective emotions online and their influence on community life. PLoS ONE, 6: e22207. doi:10.1371/ journal.pone.0022207.

Cortina, J.M. (1993). What is coefficient $\alpha$ ? An examination of theory and applications. Journal of Applied Psychology, 78, 98-104.

Costa, P.T. \& McCrae, R.R. (1989). The NEO-PI/NEO-FFI manual supplement. Odessa, FL.: Psychological Assessment Resources.

Cross, S. \& Markus, H. (1993): Gender in thought, belief, and action: a cognitive approach. In: Beall, A. \& Sternberg, R. (eds.). The psychology of gender (pp. 55-98). New York: Guilford Press.

Davis, M.H. (1983). Measuring individual differences in empathy: Evidence for a multidimensional approach. Journal of Personality and Social Psychology, 44, 113-126.

Dimberg, U. \& Lundqvist, L. (1990). Gender differences in facial reactions to facial expressions. Biological Psychology, 30, 151-159.

Dimberg, U., Thunberg, M. \& Elmehed, K. (2000). Unconscious facial reactions to emotional facial expressions. Psychological Science, 11, 86-89.

Doherty, R.W. (1997). The Emotional Contagion Scale: A measure of individual differences. Journal of Nonverbal Behavior, 21, 131-154.

Ekman, P. (1992). Facial expressions of emotions: New Findings. New Questions. Psychological Science, 3, 34-38.

George, J.M. (1990). Personality, affect, and behavior in groups. Journal of Applied Psychology, 75, 107-116.

Gouveia, V.V., Gouveia, R.S.V., Guerra, V.M., Santos, S. \& De Medeiros, E.D. (2007). Measuring Emotional Contagion: Adaptation of the Doherty Scale. Revisita de Psicologia Social, 22, 99-111.

Hatfield, E., Cacioppo, J.T. \& Rapson, L.R. (1994). Emotional Contagion. Cambridge: Cambridge University Press.

Hess, U. \& Blairy, S. (2001). Facial mimicry and emotional contagion to dynamic emotional facial expressions and their influence on decoding accuracy. International Journal of Psychophysiology, 40, 129-141.
Izard, C.E. (1992). Basic emotions, relations among emotions, and emotion-cognition relations. Psychological Review, 99, 561-565.

Kaźmierczak, M., Plopa, M. \& Retowski, S. (2007). Skala Wrażliwości Empatycznej [Empathic Sensitivity Scale]. Przeglad Psychologiczny, 50, 9-24.

Kimura, M., Yogo, M. \& Daibo, I. (2007). Development of a Japanese version of the Emotional Contagion Scale. Japanese Journal of Interpersonal and Social Psychology, 7, 31-39.

Kuczyńska, A. (1992). Inwentarz do oceny ptci psychologicznej. Podręcznik [Psychological Gender Inventory. Manual]. Warszawa: PTP.

Laird, J.D. (1984). The role of facial response in the experience of emotion: a reply to Tourangeau and Ellsworth, and others. Journal of Personality and Social Psychology, 47, 909-917.

Lundqvist, L-O. (1995). Facial EMG reactions to facial expressions: A case of facial emotional contagion? Scandinavian Journal of Psychology, 36, 130-141.

Lundqvist, L-O. (2006). A Swedish adaptation of the Emotional Contagion Scale: Factor structure and psychometric properties. Scandinavian Journal of Psychology, 47, 263-272.

Lundqvist, L-O. (2008). The Relationship between the Biosocial Model of Personality and susceptibility to emotional contagion: a structural equation modeling approach. Personality and Individual Differences, 45, 89-95.

Lundqvist, L-O. \& Dimberg, U. (1995). Facial expressions are contagious. Journal of Psychophysiology, 9, 203-211.

Lundqvist, L-O. \& Kevrekidis, P. (2008). Factor structure of the Greek version of the Emotional Contagion Scale and its measurement invariance across gender and cultural groups. Journal of Individual Differences, 29, 121-129.

Lundqvist, L-O., Carlsson, F., Hilmersson, P. \& Juslin, P.N. (2009). Emotional responses to music: experience, expression, and physiology. Psychology of Music, 37, 61-90.

Neumann, R. \& Strack, F. (2000). "Mood contagion": the automatic transfer of mood between persons. Journal of Personality and Social Psychology, 79, 211-223.

Papousek, I., Schulter G. \& Lang, B. (2009). Effects of emotionally contagious films on changes in hemisphere-specific cognitive performance. Emotion, 51, 1018-1022.

Rueff-Lopes, R. \& Caetano, A. (2012). The Emotional Contagion Scale: factor structure and psychometric properties in a Portuguese sample. Psychological Reports, 111, 898-904.

Shields, S.A. (2002). Speaking from the heart: Gender and the social meaning of emotion. Cambridge: Cambridge University Press. 
Stepper, S. \& Strack, F. (1993). Proprioceptive determinants of affective and nonaffective feelings. Journal of Personality and Social Psychology, 56, 339-353.

Strelau, J. (1996). The regulative theory of temperament. Personality and Individual Differences, 20, 131-142.

Wild, B., Erb, M. \& Bartels, M. (2001). Are emotions contagious? Evoked emotions while viewing emotionally expressive faces: quality, quantity, time course and gender differences. Psychiatry Research, 102, 109-124.

Winton, W.M. (1986). The role of facial response in self-reports of emotion: A critique of Laird. Journal of Personality and Social Psychology, 50, 808-812.

Wróbel, M. (2007). Pomiar podatności na zarażenie emocjonalne. Wstępna analiza własności psychometrycznych polskiej adaptacji Emotional Contagion Scale [Measuring susceptibility to emotional contagion: the preliminary analysis of the psychometric properties of the Polish adaptation of the Emotional Contagion Scale]. Nowiny Psychologiczne, 3, 69-92.

Wróbel, M. (2009). Polish adaptation of the Emotional Contagion Scale: Factor structure and psychometric properties. In: A. Błachnio \& A. Przepiórka (eds.). Closer to emotions III (pp. 167-181). Lublin: Wydawnictwo KUL.

Zawadzki, B. \& Strelau, J. (1995). Podstawy teoretyczne, konstrukcja i własności psychometryczne inwentarza: "Formalna Charakterystyka Zachowania - Kwestionariusz Temperamentu" [Theoretical basis, construction and psychometric properties of the questionnaire: "Formal Characteristics of Behaviour - Temperament Inventory”]. Studia Psychologiczne, 33, 49-96.

Zawadzki, B., Strelau, J., Szczepaniak, P. \& Śliwińska, M. (1998). Inwentarz Osobowości NEO-FFI Costy i McCrae. Podręcznik [Costa and McCrae's NEO-FFI Personality Inventory. Manual of Polish adaptation]. Warszawa: Pracownia Testów Psychologicznych PTP. 